Journal of Al-Azhar University Engineering Sector

Vol. 14, No. 53, October, 2019, 1616-1632

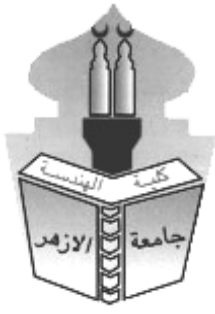

\title{
DESIGN DETERMINANTS FOR PEDESTRIAN CIRCULATION FOR EGYPTIAN RAILWAY STATIONS
}

\author{
*Esraa Hany Fadel ${ }^{1}$, Mohamed Ezzat Said ${ }^{1}$, Mohamed Farid Aho \\ El Ela ${ }^{1}$ and Hisham Adly Mohamed ${ }^{2}$ \\ ${ }^{1}$ Epartment of Architecture, Shoubra Faculty of Eng. Banha University, Egypt. \\ ${ }^{2}$ Department of architecture, faculty of Eng. Al salam higher institute, Cairo, Egypt. \\ *Corresponding author E-mail: Esraa_hany94@yahoo.com
}

\begin{abstract}
S
The acceleration of the implementation of development plans (Urban) (1) in the modern era stressed the importance and development of rail ways systems in the horizontal urban spread and decentralization, which was as well as public transport systems of land is characterized by ease of operation and relatively low cost used to transport volumes and large quantities of goods for long distances As well as passenger transport at high speeds, full comfort, safety and environmental emission control (2) It should be noted that the four models initiated by the Railways as an element for the models In 2007, the design determinants of the passenger circulation and the impact of space per person (3) within these models were re-evaluated of the recent social, economic and technological developments in the country, in order to comfort pedestrian and encourage the use of public transportation systems and railways in particular. By studying the design determinants of some global experiments, we can propose after the design
\end{abstract} determinants of Egypt.

KEY WORDS: Determinants Of The Design Of Railway Stations, Design. Elements Of Railway Stations, Traffic Paths Within Railway Stations, Design Models For Railway Stations, Design Determinants Of The Pathways Of The Movement Of Observers To The Global Experiences

$$
\begin{aligned}
& \text { المحددات التصميمية لعناصر حركة المشاة في محطات سكك حديد مصر }
\end{aligned}
$$

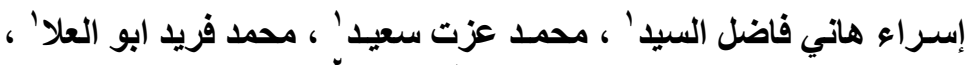

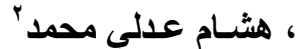

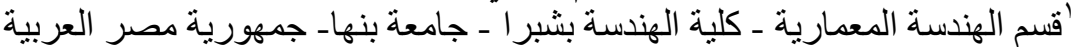

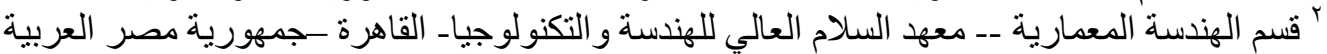

$$
\begin{aligned}
& \text { الملخص: }
\end{aligned}
$$

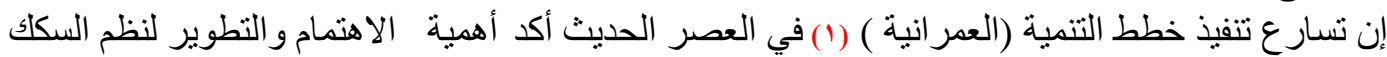

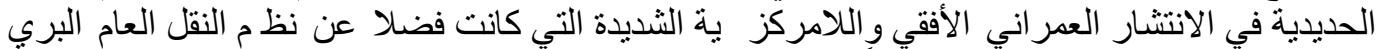

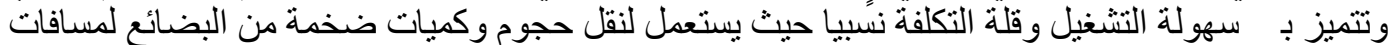

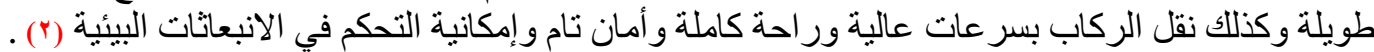

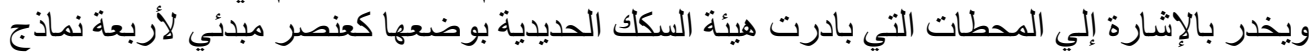




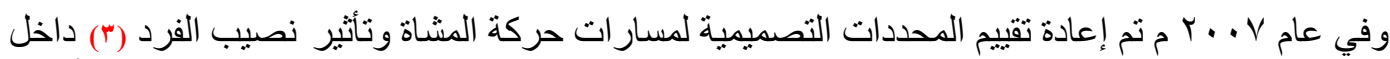

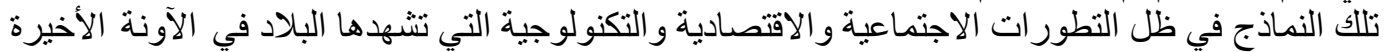

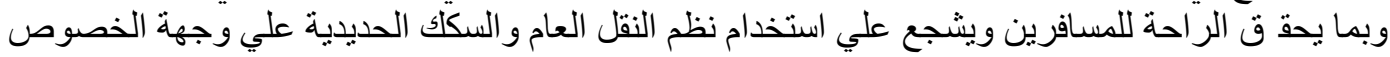

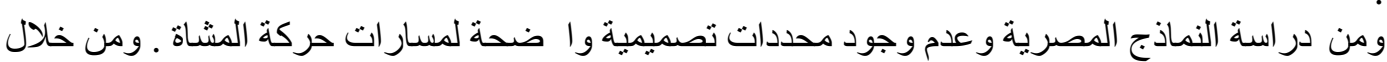

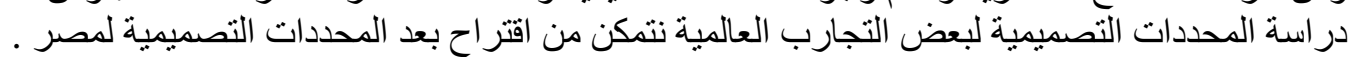

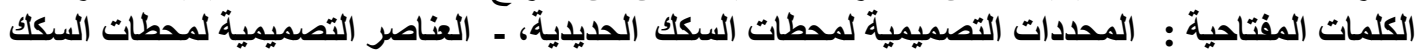

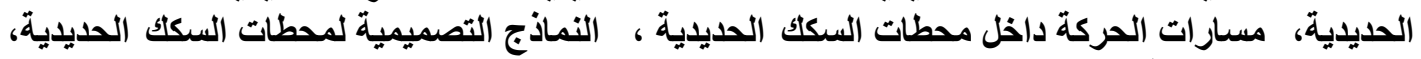

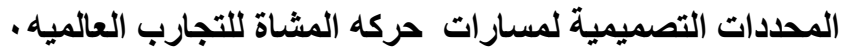

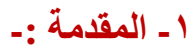

تلعب السكك الحديدية دور ا هاما في منظومة النقل العام لما تتمتع بة من مز ايا كبيرة من حيث استهلاك

الوقود وتكاليف التشغيل وتحقيق الأمن و الحفاظ علي البيئة.

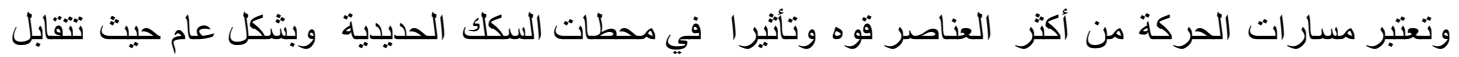

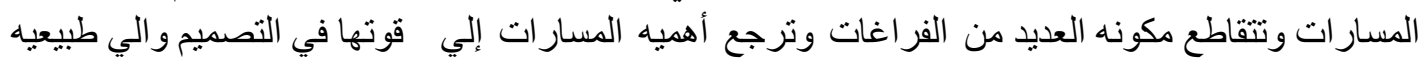

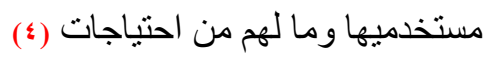

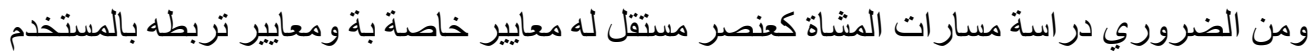

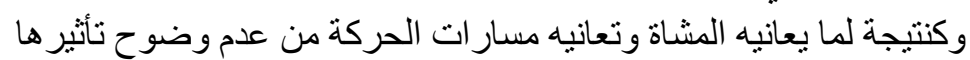

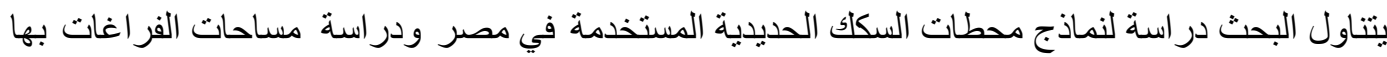
و إعداد المستخدمين ومسار ات الحركة لهما و نصيب الفرد داخل المحطات و ودراسة المحددات التصميمية للتجارب العالمية ومن خلال ذلك ينقسم البحث إلي :-

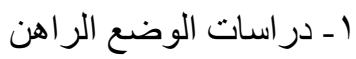

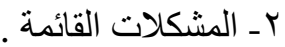

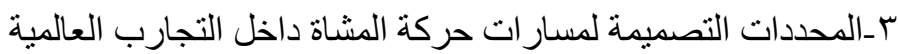

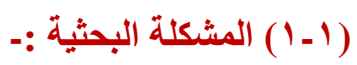
ا ـ عدم وجود انسيابية في حركة الركاب ( القادمين - المغادرين) داخل المحطات ـ وحدوث تكدس للمحطات في ساعات الذروة r - قصور في تحقيق أمان المشناة علي الأرصفة .

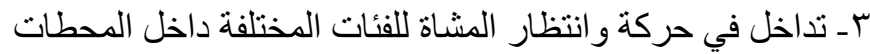

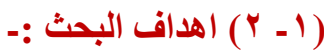

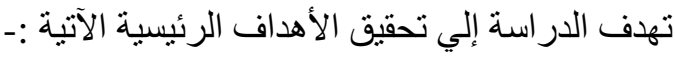

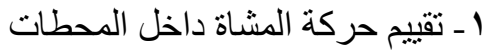

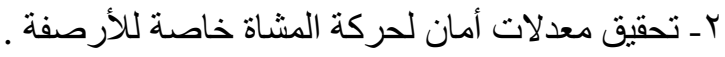

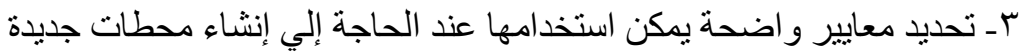




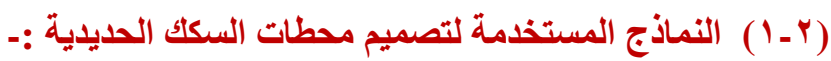

قامت هيئة السكك الحديدية بوضع أربعة نماذج مختلفة لمحطات السكك الحديدية في مصر وتم تصنيف هذة النماذج طبقا لوظيفة المحطات داخل الثبكات ـ ولقد اقتصر تصميم هذه النماذج علي تحديد التوزيع المكاني

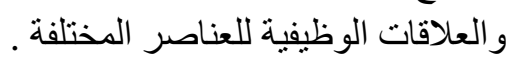

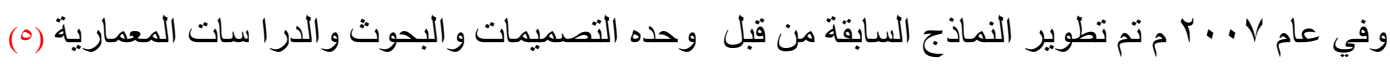

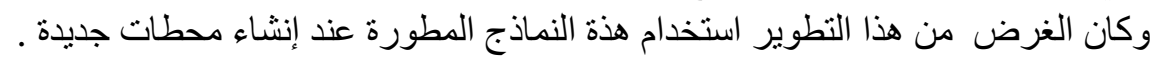

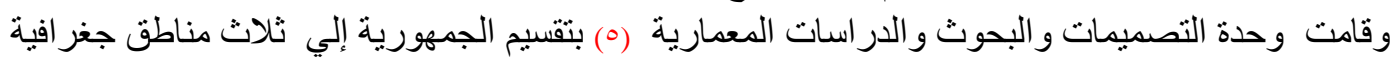

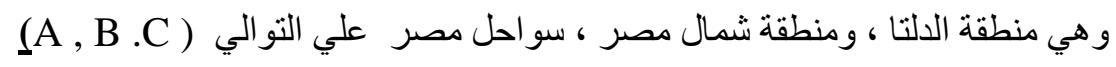

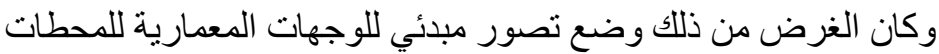

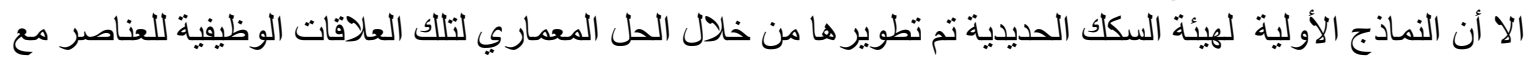

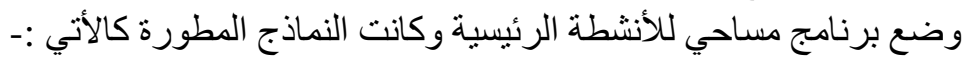

$$
\text { نموذج Aم نموذج }
$$

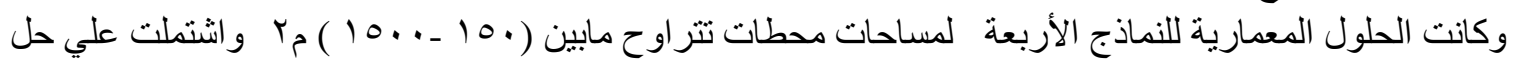
للعناصر الرئيسية (المداخل ـ منافذ بيع التذاكر - الارصفة ـ المحلات التجارية ـ صالات الانتظار ـ الفر اغات الإدارية ـ الخدمات ) 


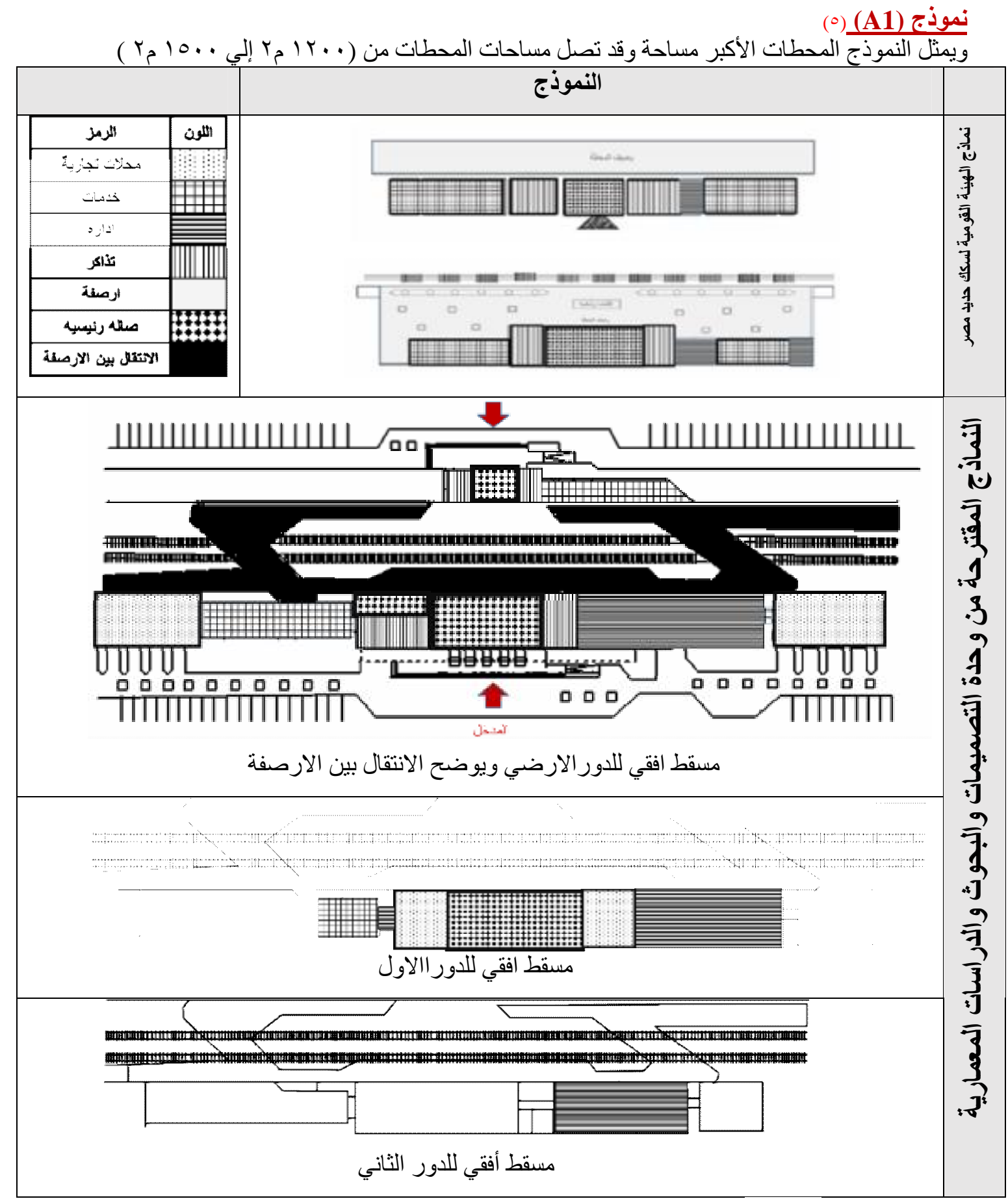

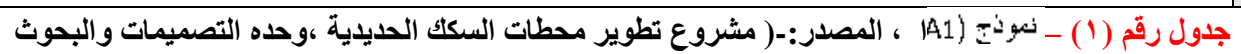

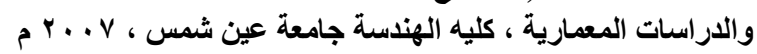




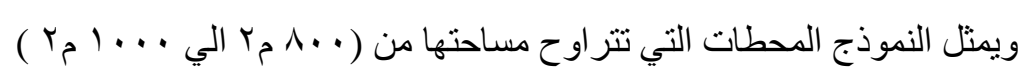

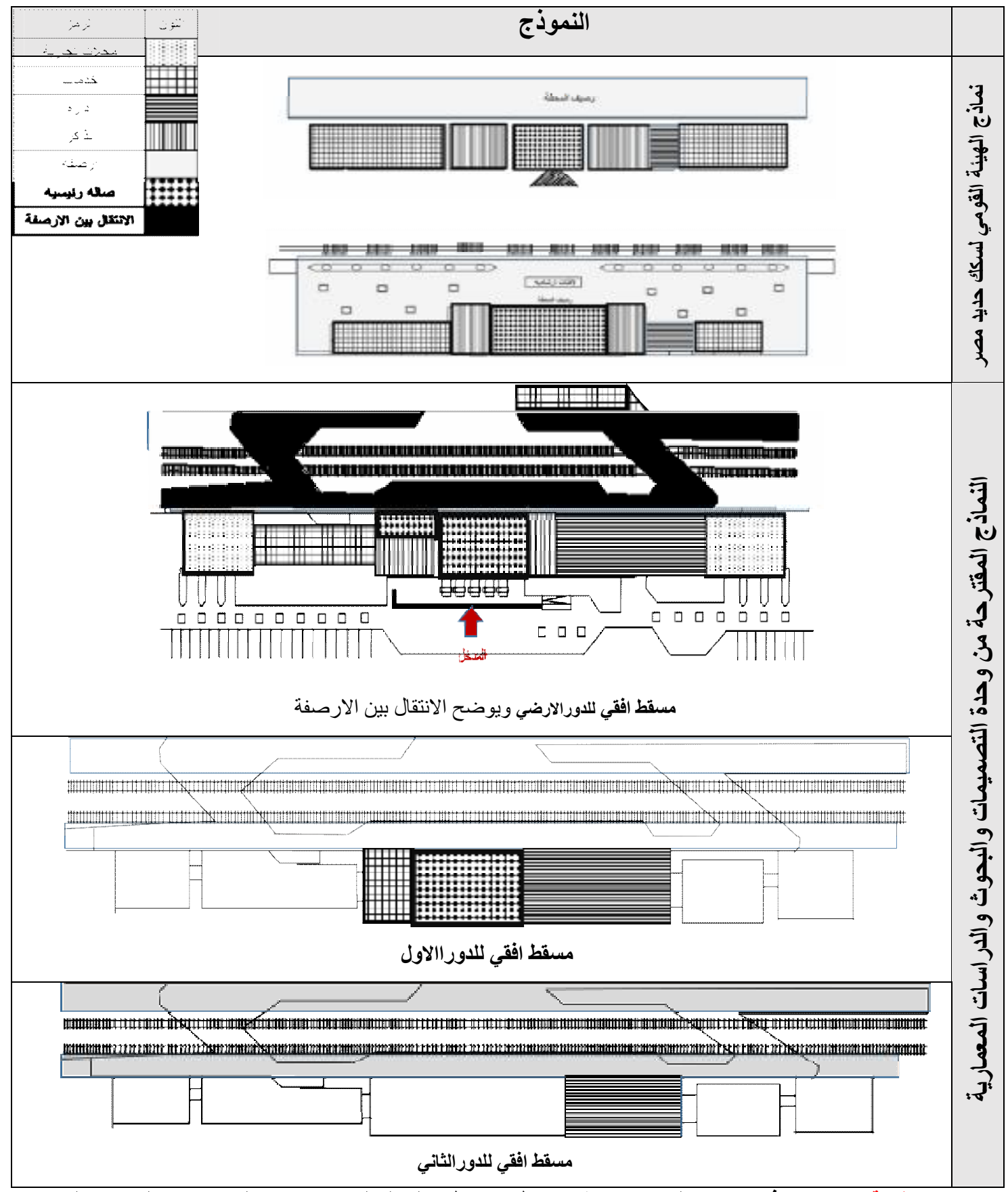

جدول رقم (ץ) - نموذج (A2) / المصدر:-( مشروع تطوير محطات السكك الحديايه ،وحده التصميمات والبحوث و الاراسات

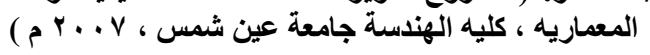

(0) (A3) نموذج 


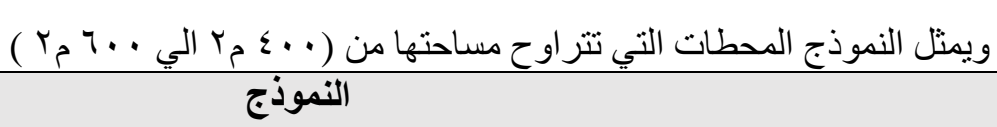

\begin{tabular}{|c|c|}
\hline ملر & alla \\
\hline 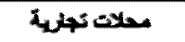 & \\
\hline etass & \\
\hline المالر & \\
\hline تانمز & \\
\hline ارمسية & \\
\hline صلاد رئوسبه & \\
\hline 2hajn ow Jwry & \\
\hline
\end{tabular}
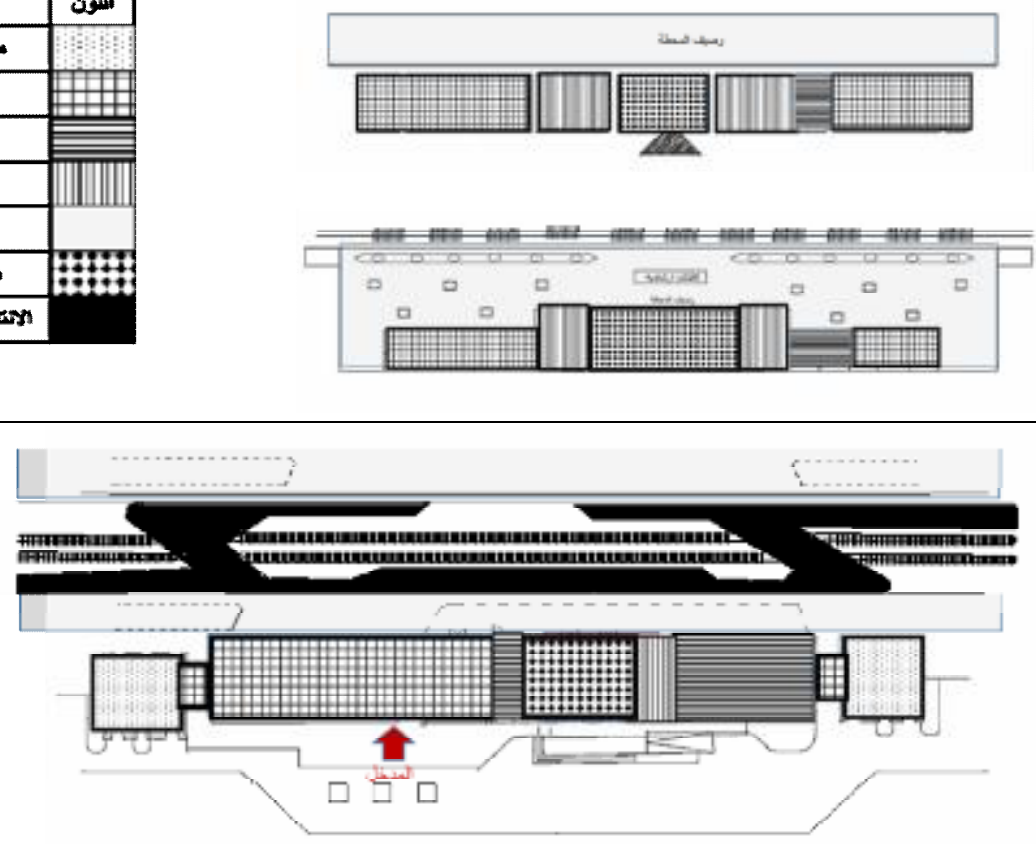

مسقط افقي للاور الارضي ويوضح الانتقال بين الارصفة

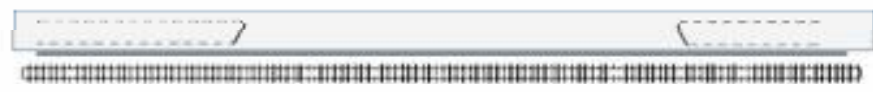

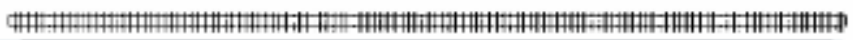

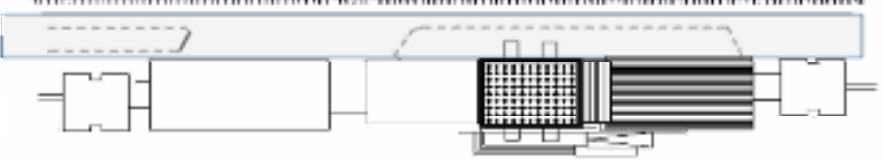

$$
\text { مسقط افقي للدور الاول }
$$

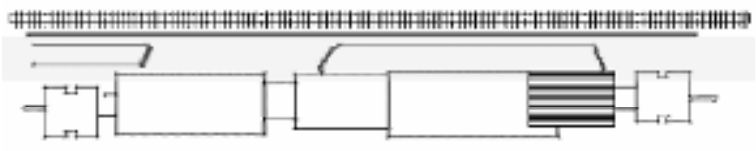

$$
\text { مسقط افقي للدور الثاني }
$$

جدول رقم (ب) - نموذج (A3) / المصدر:-( مشروع تظوير محطات السكك الحديديه ،وحده التصميمات والبحوث والدراسات

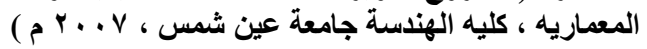

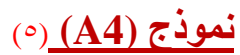

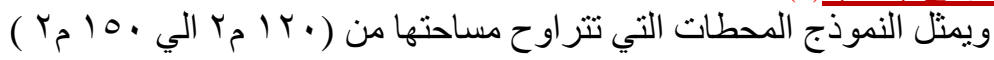




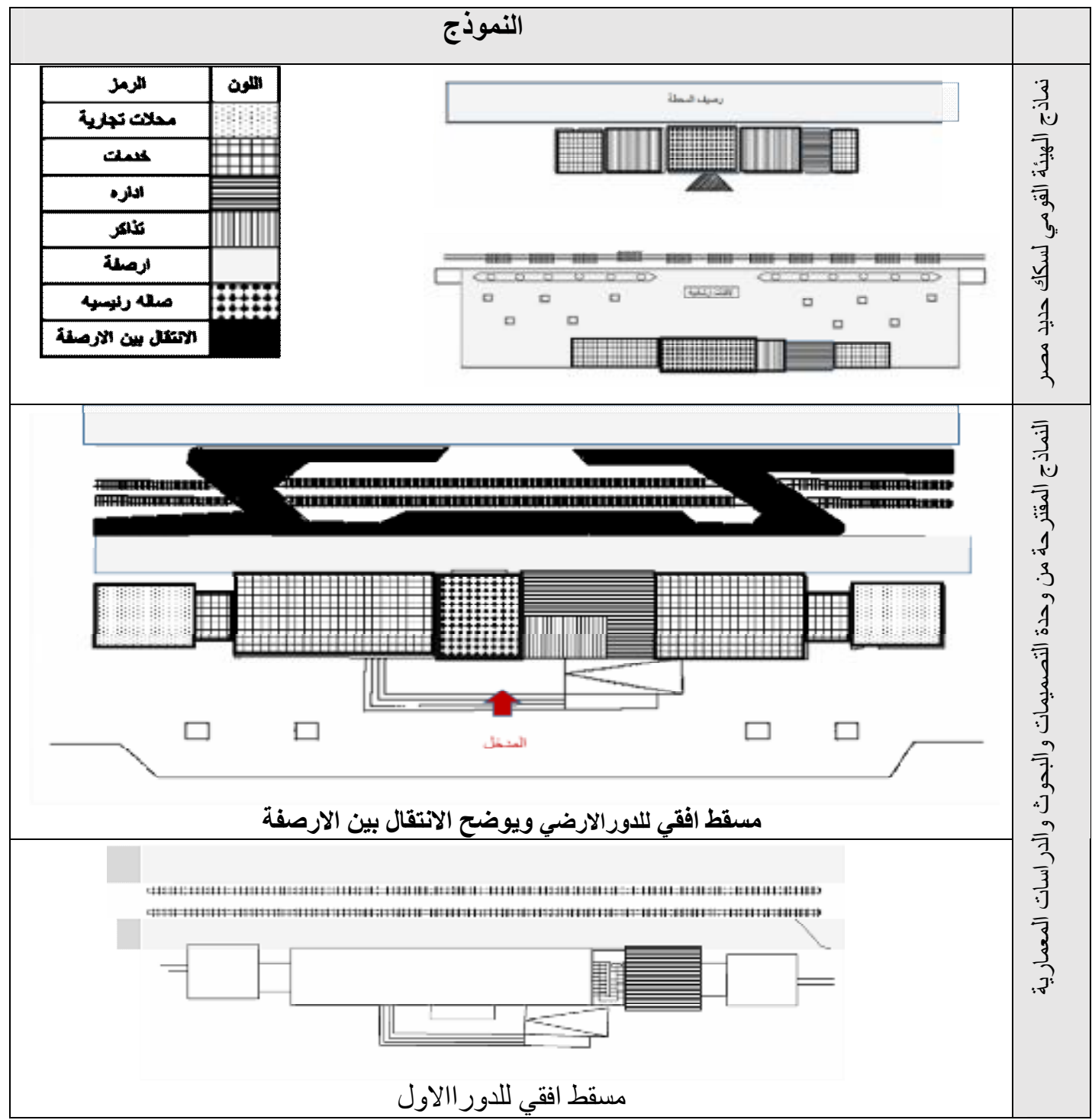

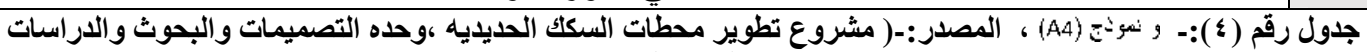

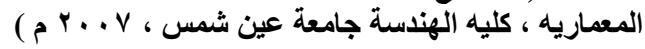

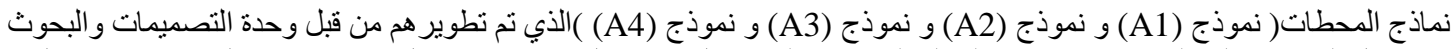

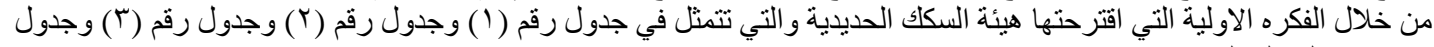

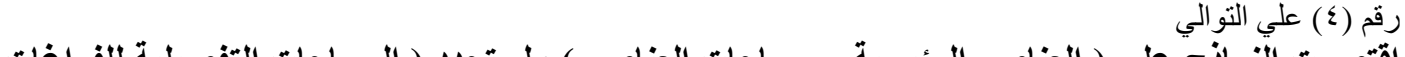

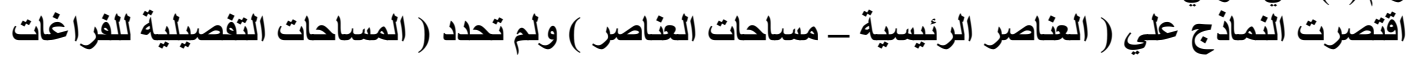

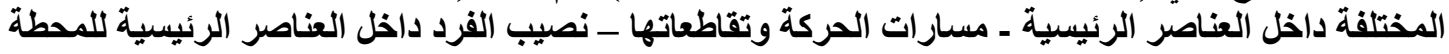

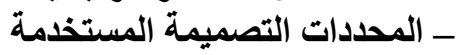

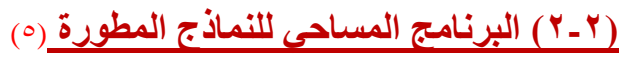


من خلال در اسة البرنامج المساحي توصل الي عدم وجود مروذ ة في التصميم تسمح باستيعاب الاعداد المتز ايدة

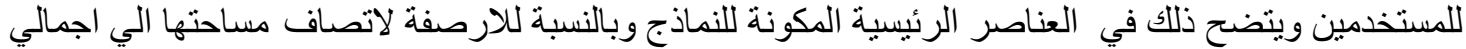

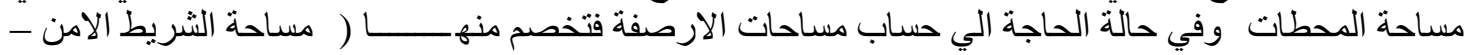

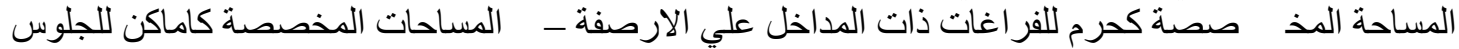

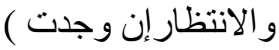

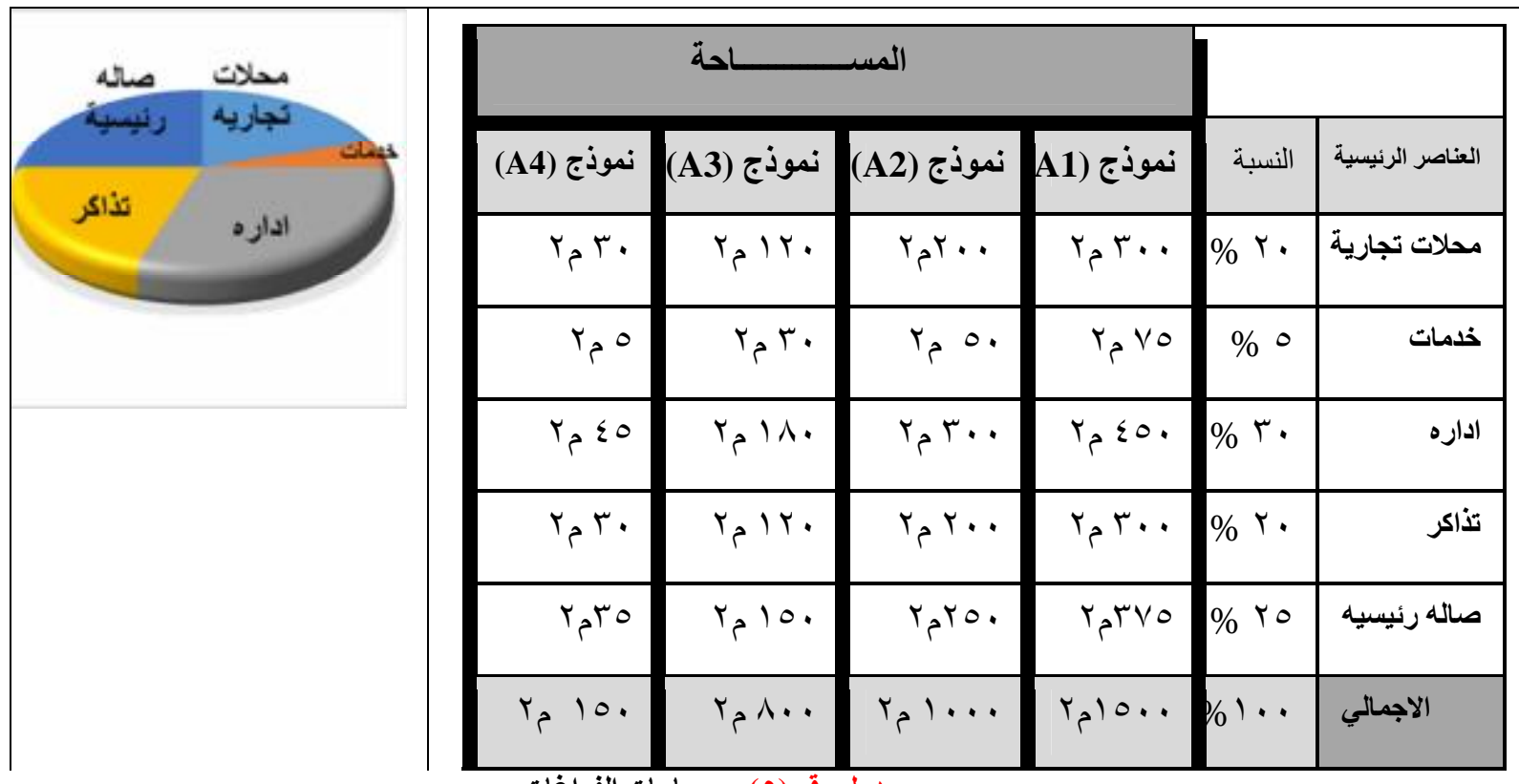

جدول رقم (ه) - مساحات الفراغات

/ المصدر:-( مشروع تطوير محطات السكك الحديديه ،وحده التصميمات والبهات البحوث و الاراسات المعماريه ،

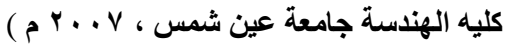

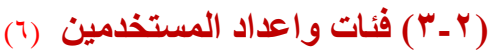
تنقسم فئات المستخدمين لتلات النماذج المين للمحطات للأتي

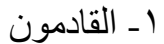

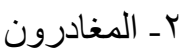

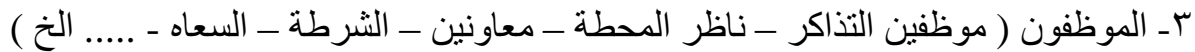

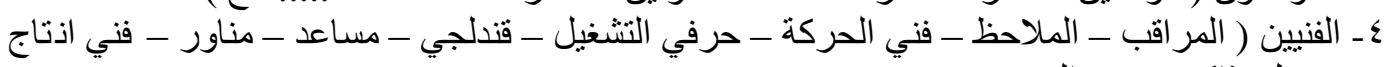

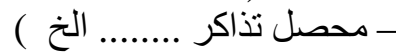

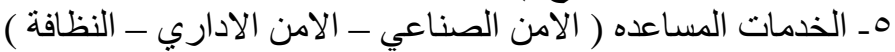

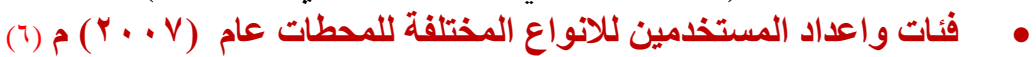

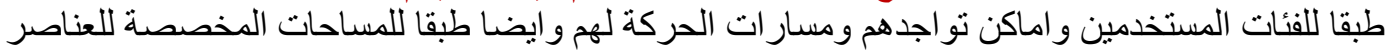

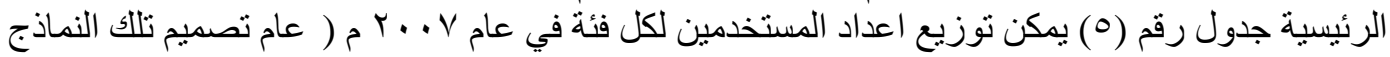

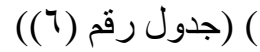




\begin{tabular}{|c|c|c|c|c|}
\hline \multicolumn{4}{|c|}{ 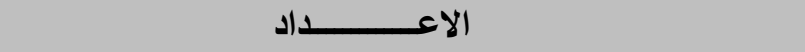 } & \\
\hline نموذج (A4) & نموذج (A3) & نموذج (A2) & نموذج (A1) & القئـات \\
\hline 001 & rq & 79.7 & rorrt & عدد الركاب (القادمون ) \\
\hline .001 & $r q \leq 0$ & 79.7 & TORYT & عدد الركاب (المغادرون ) \\
\hline 1. & 11 & r. & 90 & عدد الموظفين \\
\hline ir & r. & r. & 9. & عدد الفنيين \\
\hline 1. & 11 & rr & ro & خدمات مساعدة \\
\hline $11 \leqslant 1$ & ०१५१ & IrAA0 & 0.144 & الاجمالي (فرد / اليوم ) \\
\hline o. & ro. & OVA & r 119 & الاجمالي (فرد / الساعة ) \\
\hline
\end{tabular}

جدول رقم (7) - اعداد المستخدمين لعام V. . . م م / المصدر:-( الهيئة القومية لسكك حديد مصر )

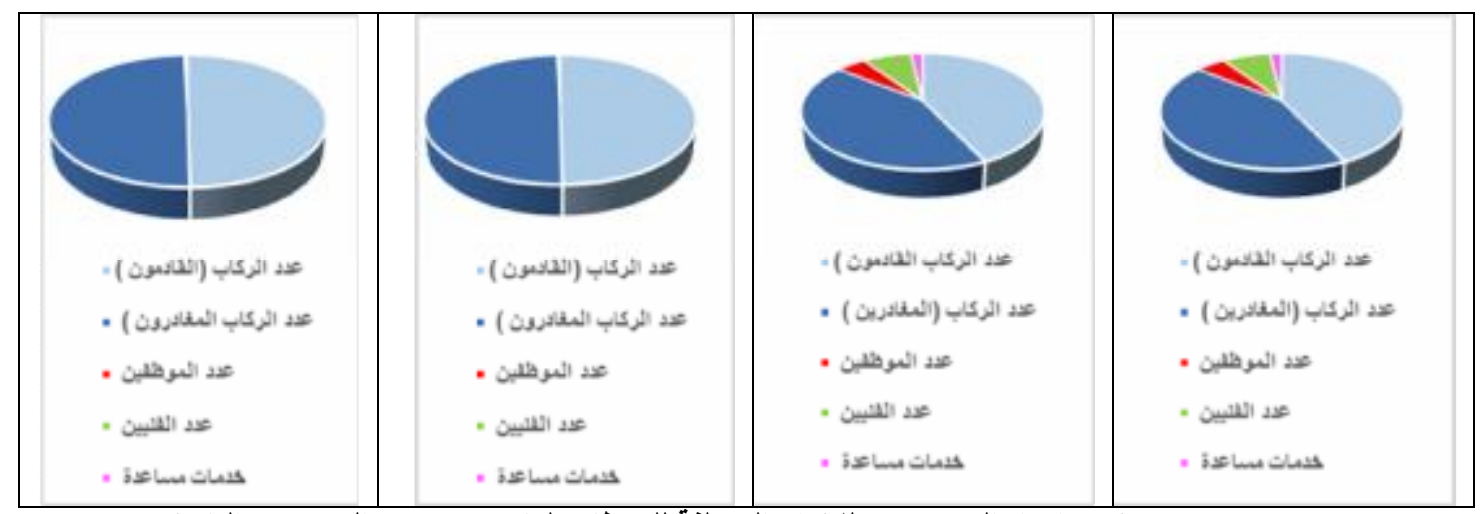

نسب اعداد المستخدمين للانواع المختلفة للمحطات لعام V ... م / / المصدر:-( الباحث) 


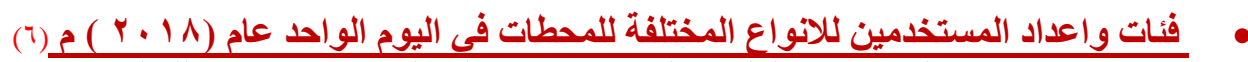

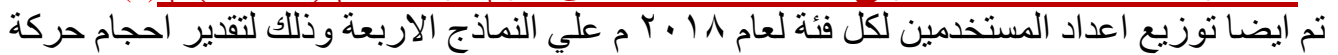

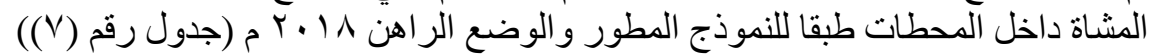

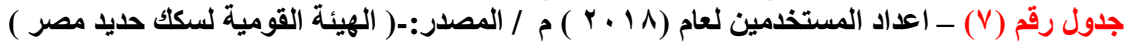

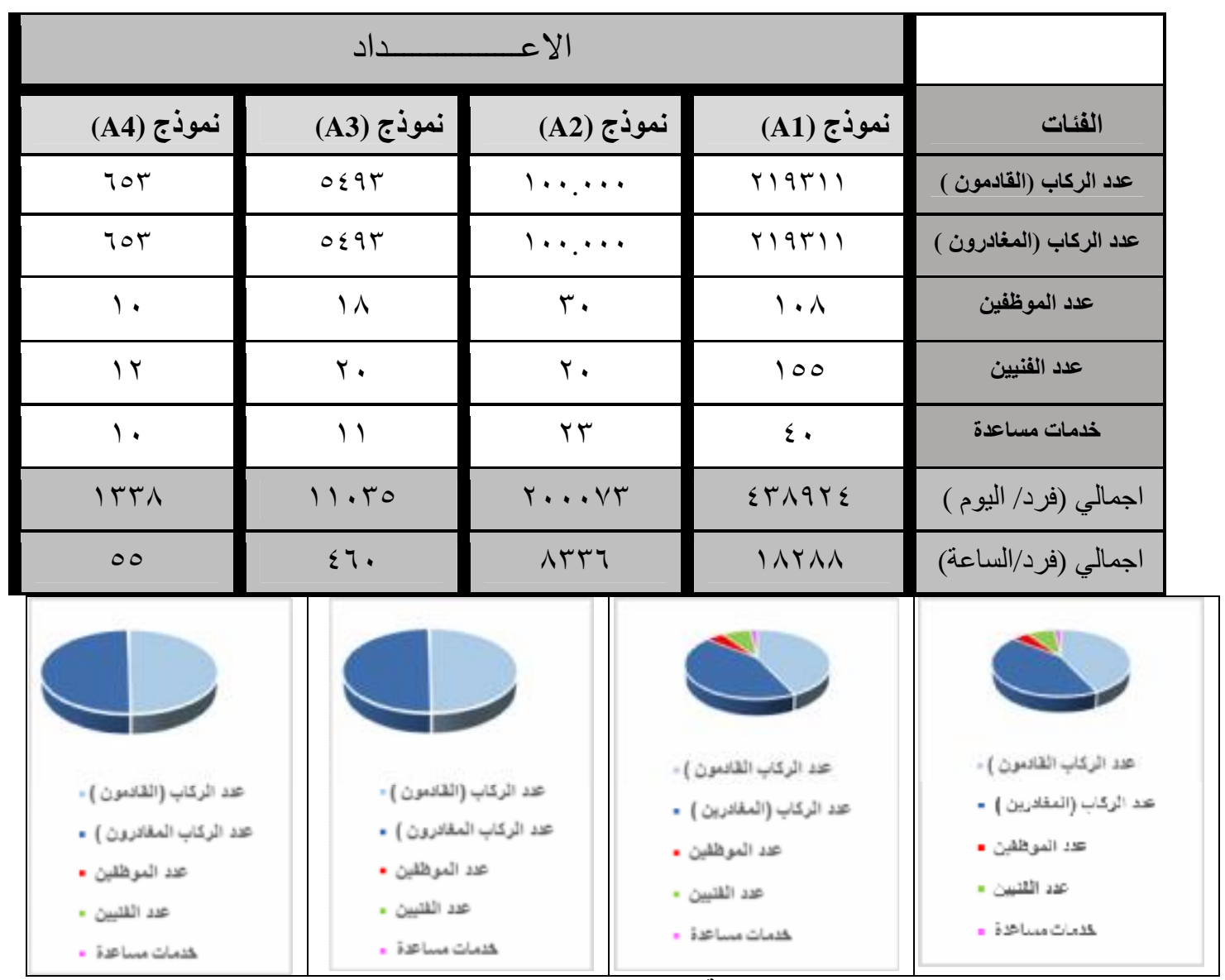

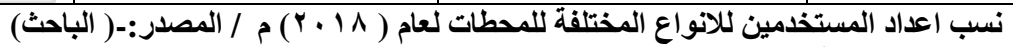

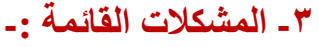

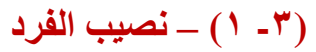

تظهر النماذج المطورة عدم وجود محددات تصميمية واضحة لعناصر حركة المشاة داخل المحطات

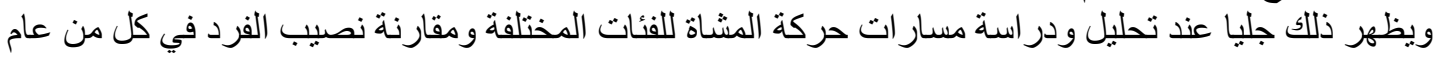

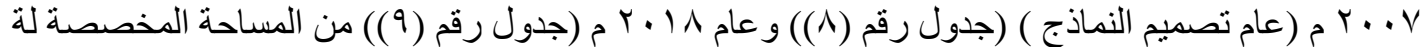
داخل الفر اغات المختلفة 
نصيب الفرد داخل انواع المحطات المختلفة لعام (Y. V ) مد

\begin{tabular}{|c|c|c|c|c|c|c|c|c|c|c|c|c|}
\hline & \multicolumn{2}{|c|}{ نموذج ( A4) } & & \multicolumn{2}{|c|}{ نموذج ( A3) } & & \multicolumn{2}{|c|}{ نموذج ( A2) } & & \multicolumn{2}{|c|}{ نموذج ( A1) } & \\
\hline نصبي الفرد & الالفراد الفرد في & المباحة & نصريب & الأفر الفرد فيط & إمباحة & نصيب & الالفراد الفرد فيط & المسادة & نصريب & الالفراد الفرديط & لمساحة & الرئيسية \\
\hline$r$ & 0. & 10. & r.r. & ro. & $\wedge \ldots$ & I.v. & OVA & $1 \ldots$ & $\cdot{ }^{v}$ & 5119 & $10 \ldots$ & مالي \\
\hline
\end{tabular}

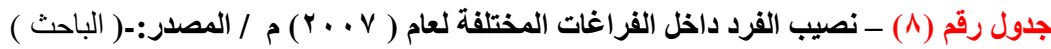

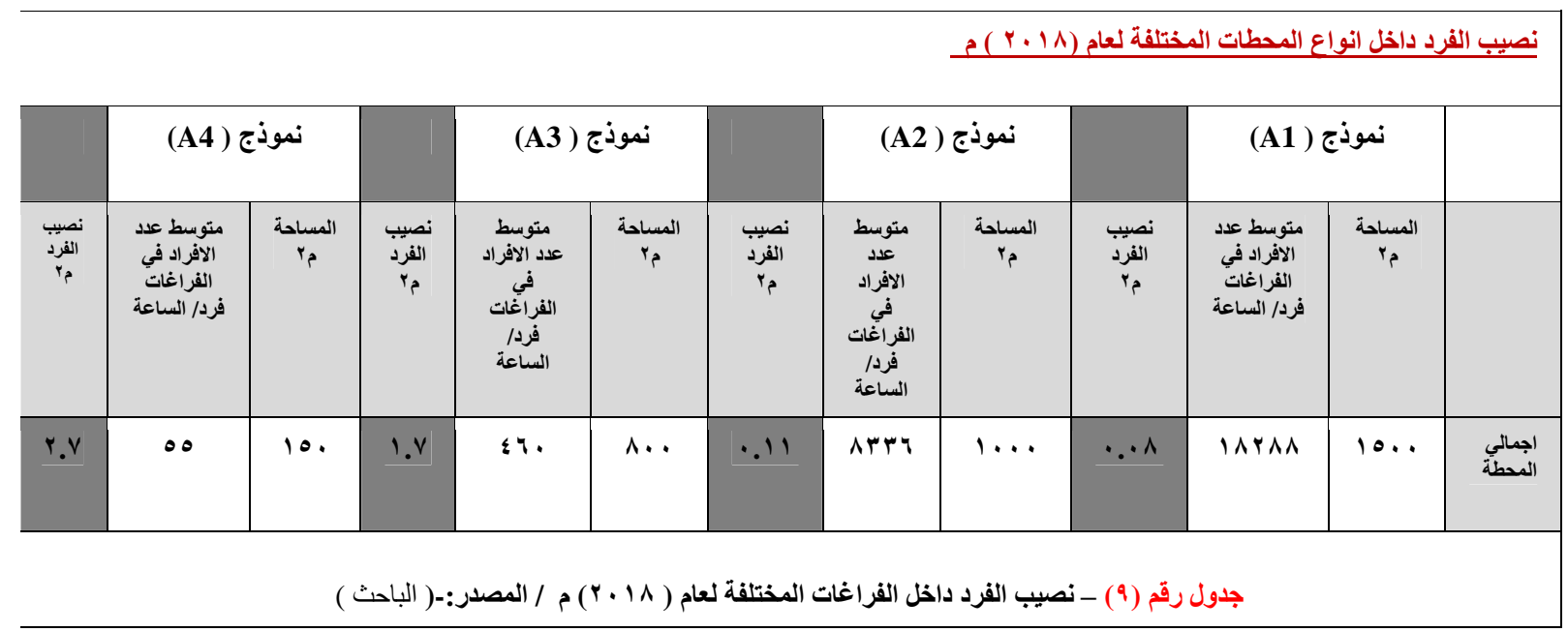

وبالتالي فان نصيب الفرد داخل المحطات يقل بزياده اعداد المستخدمين و تصبح مساحات الفر اغات غبر كافية

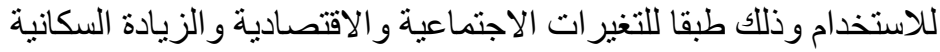

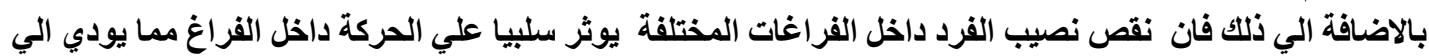

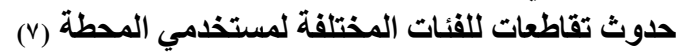

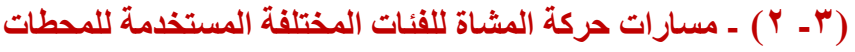

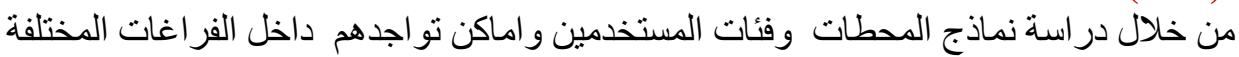

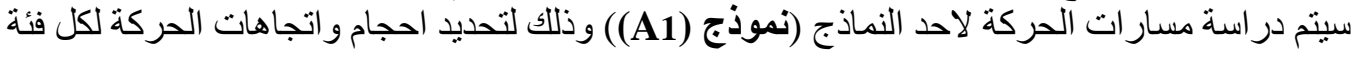




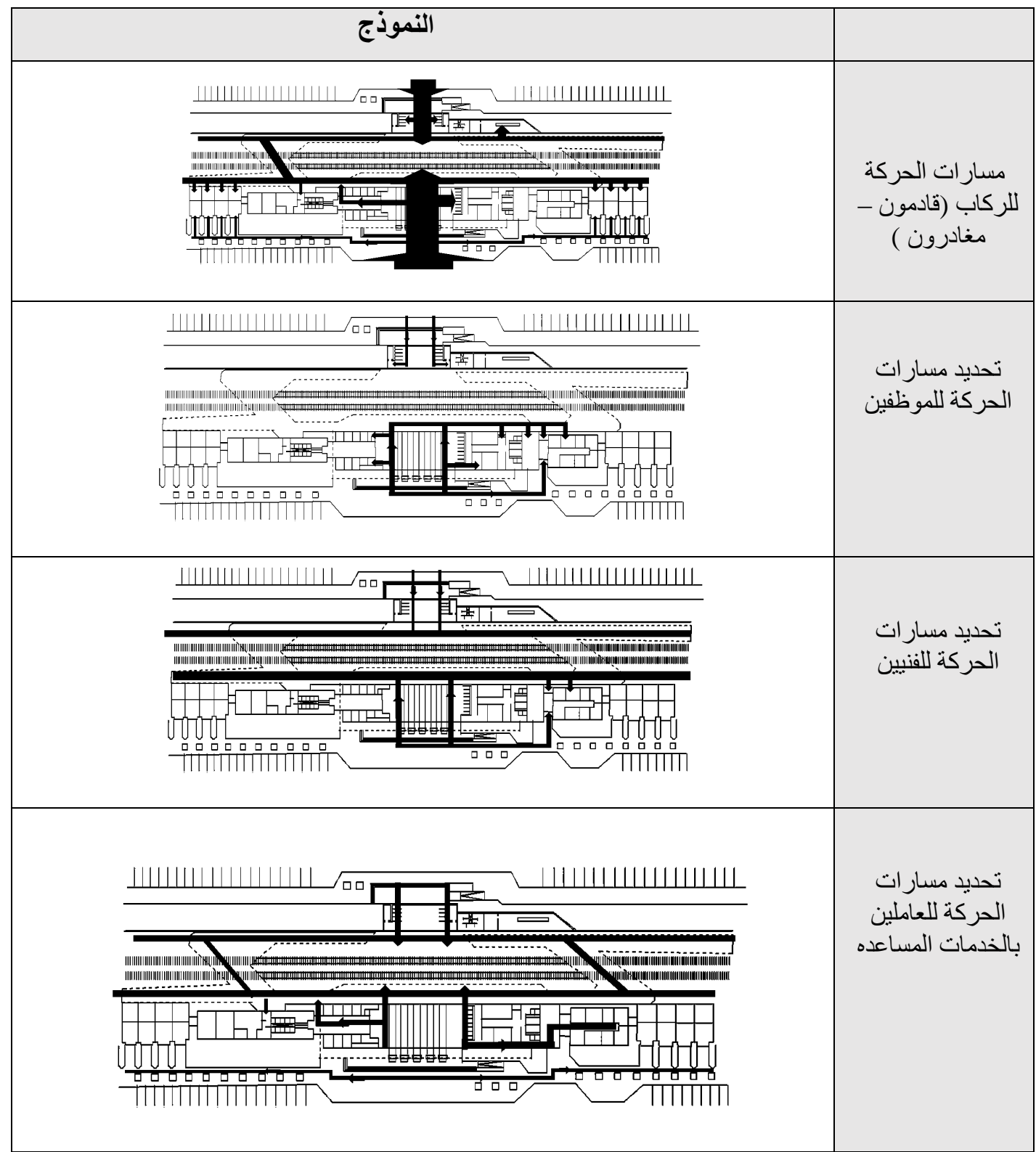

جدول رقم ( • () - تقاطعات مسارات الحركة داخل نموذج / المصدر:-( الباحث )

من خلال تحديد مسار ات الحركة للفئات المستخدمة للمحطة وجد انه هناك فر اغات تتفاطع فيها مسار ات الحركة

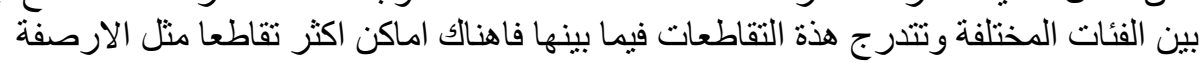

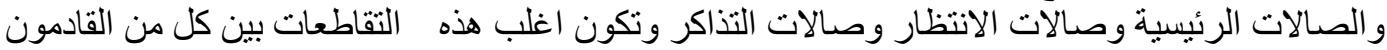

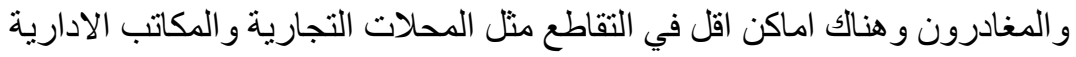



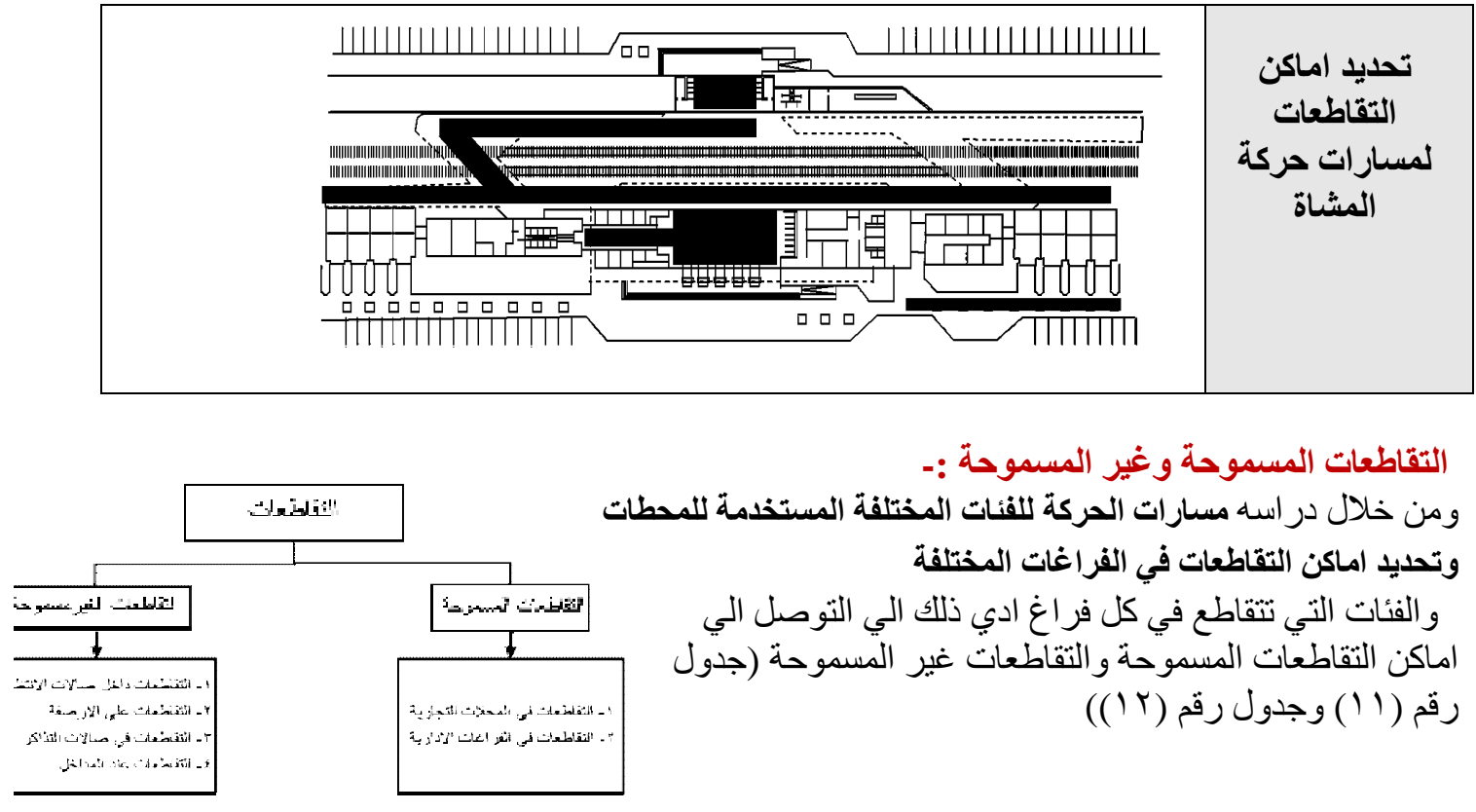

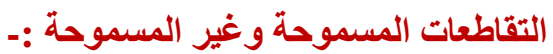

التقاطعات غير المسموحة لمختلف المستخدمين

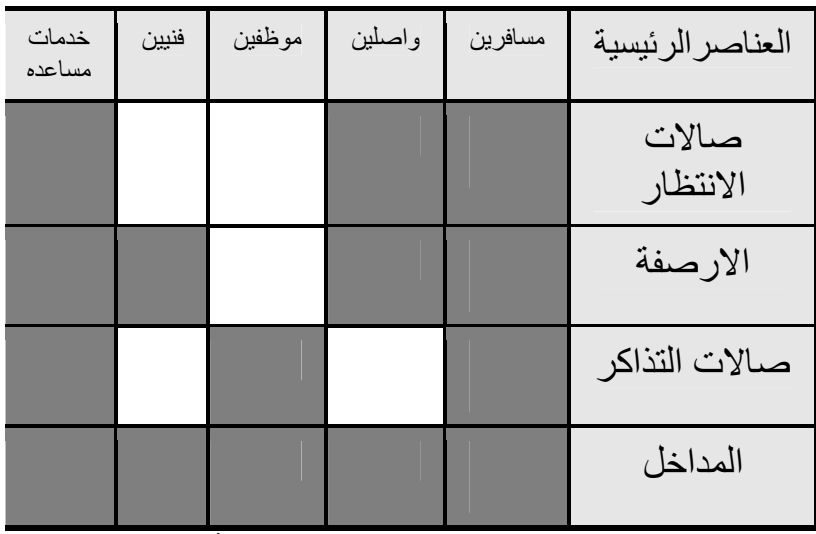

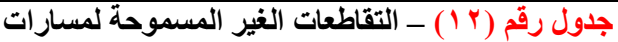
حركة المشاة داخل نموذج (A4) / المقات الفير المدر:-( الباحث)
التقاطعات المسموحة لمختلف المستخدمين

\begin{tabular}{|c|c|c|c|c|c|}
\hline خشاعدات & فنيين & موظفين & واصلين & مسافرين & العناصر الرئيسية \\
\hline & & & & & المحلات التجارية \\
\hline & & & & & الادارة \\
\hline
\end{tabular}

جدول رقم (11 ) - التقاطعات المسموحة لمسارات

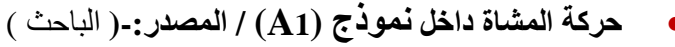

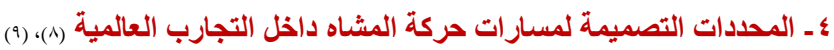

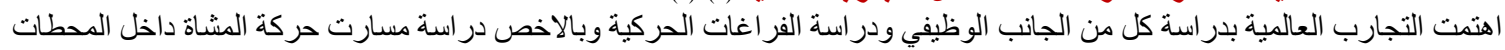

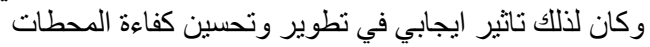

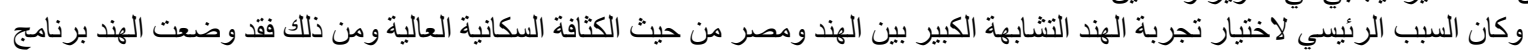

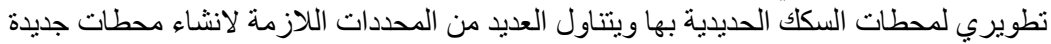

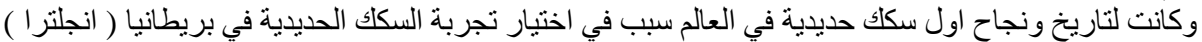
وتعتبر تجربة كل من الهند ومصر من التجارب المشتقة من التجربة البريطانية • 


\begin{tabular}{|c|c|c|}
\hline 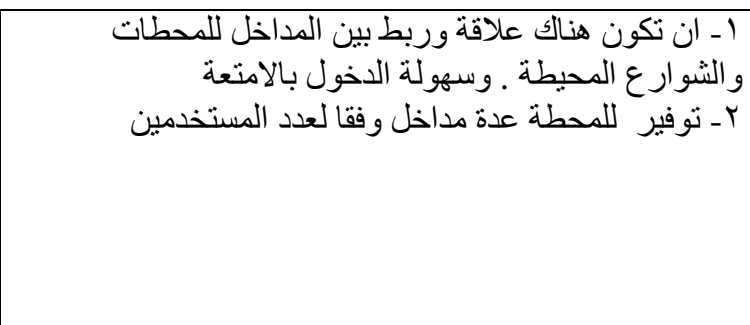 & 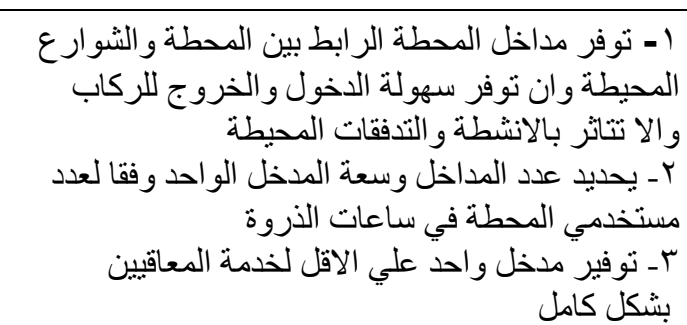 & \\
\hline 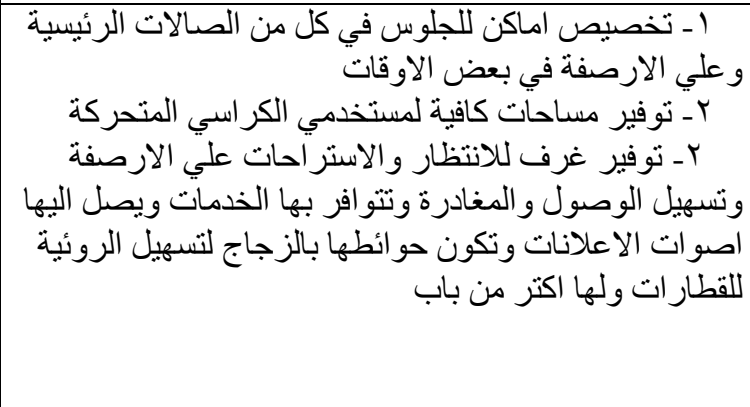 & 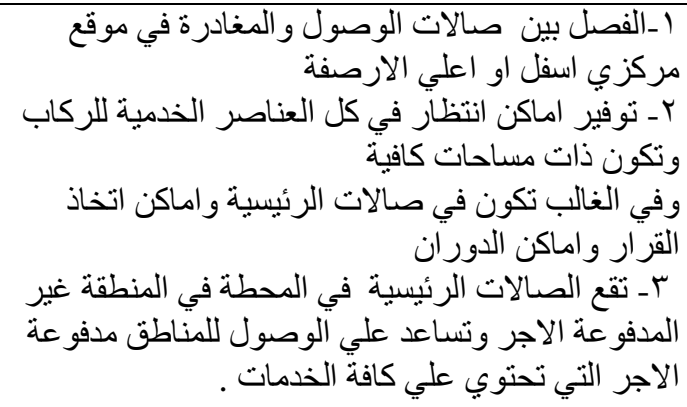 & $=$ \\
\hline 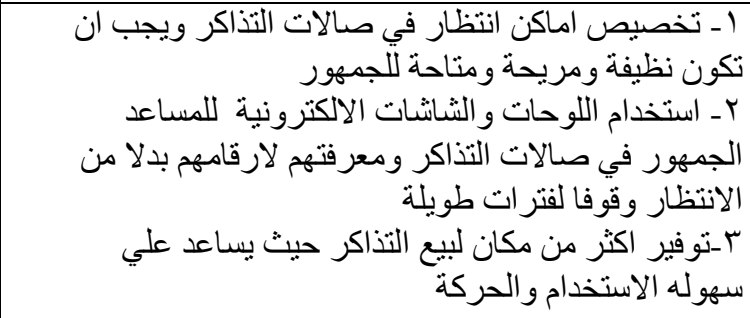 & 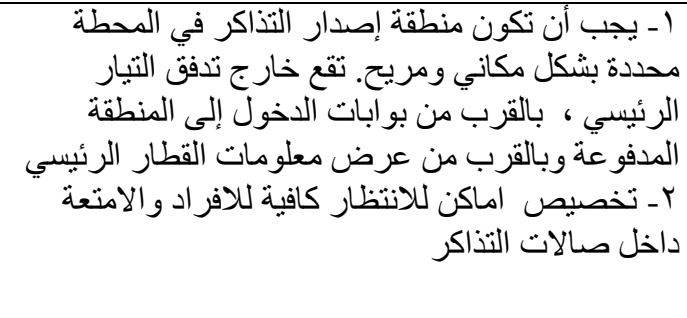 & 雲 \\
\hline 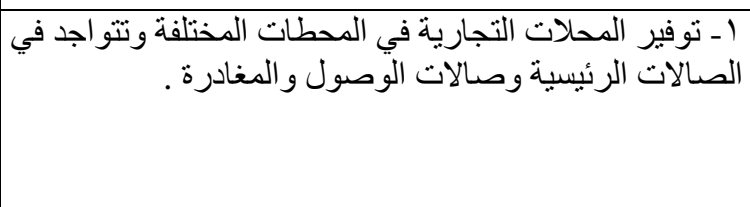 & و المغادرة وفي كل من المناطق المدات في الماتلات الوصهول الغير مدفوعة & 高 \\
\hline
\end{tabular}




\begin{tabular}{|c|c|c|}
\hline 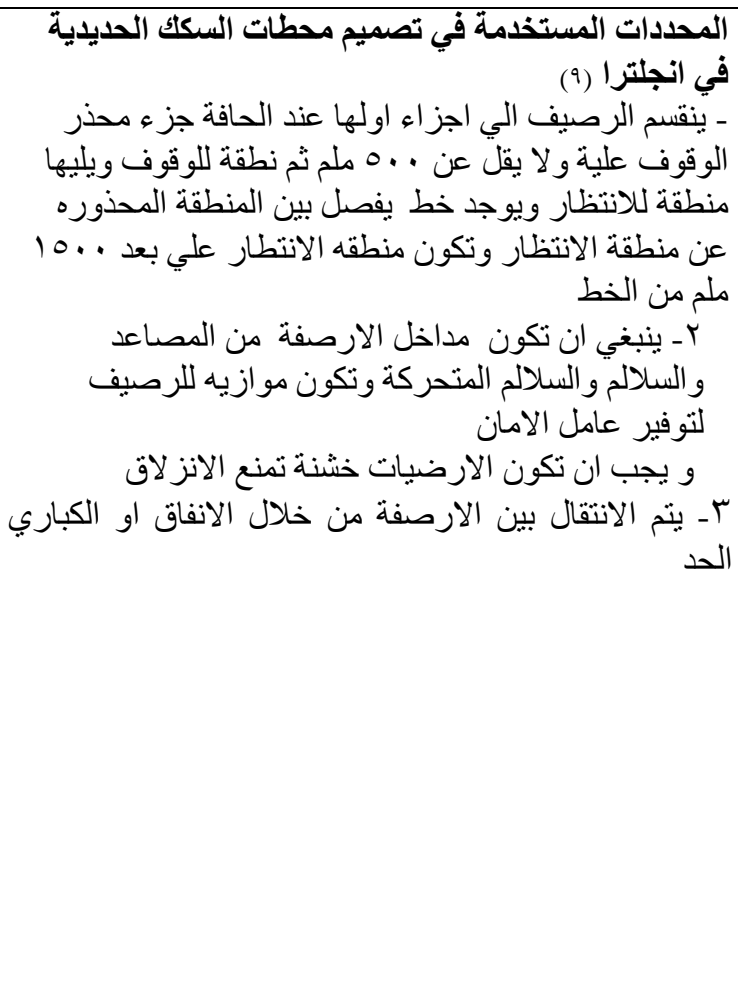 & 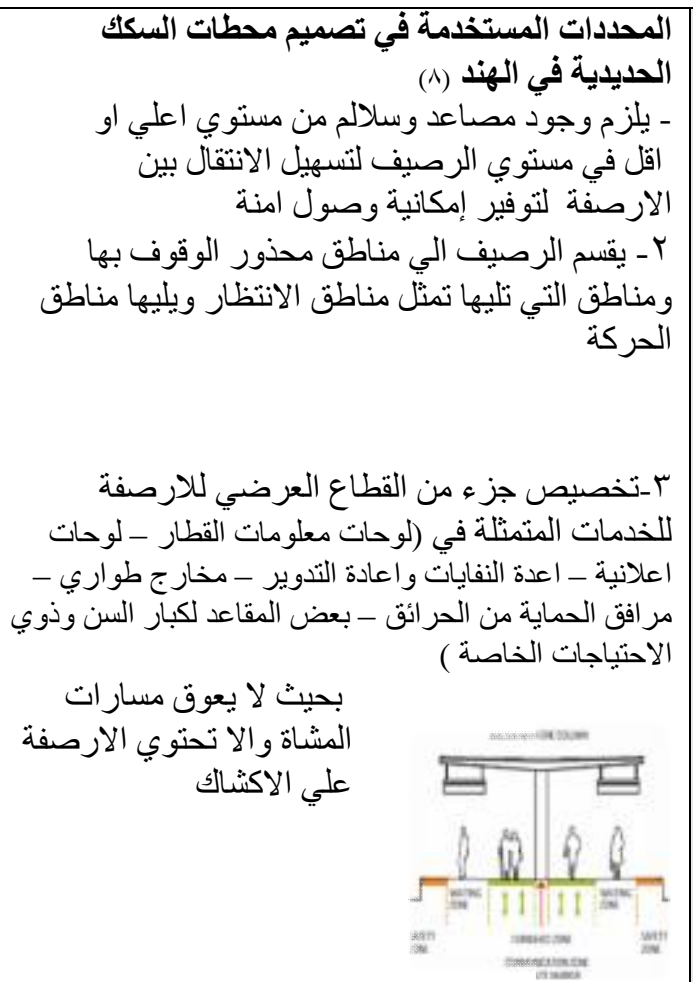 & g. \\
\hline 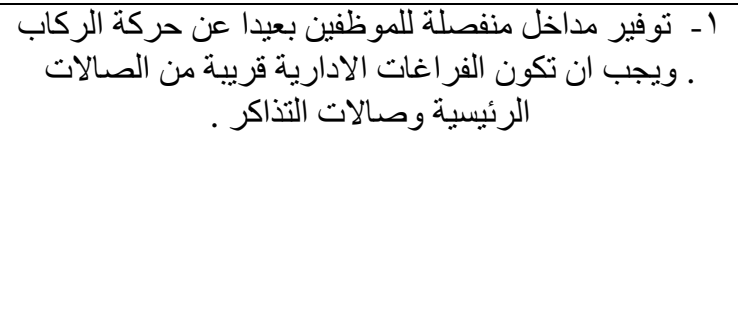 & 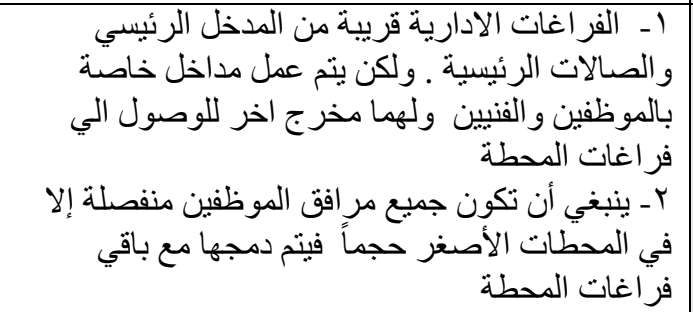 & 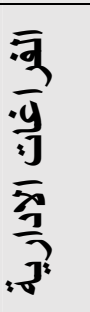 \\
\hline •. 1 مY من اجمالي مساحة المحطة & 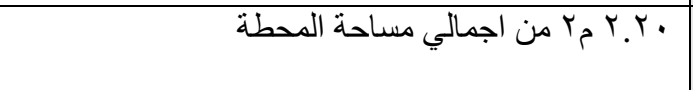 & 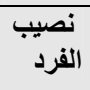 \\
\hline 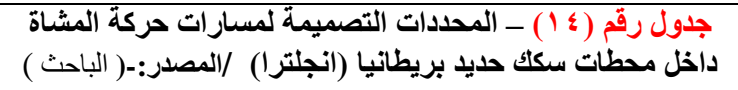 & 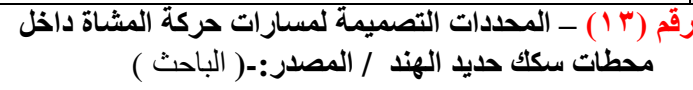 & \\
\hline
\end{tabular}




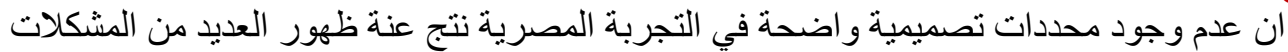
- النتائج والتوصيات :-

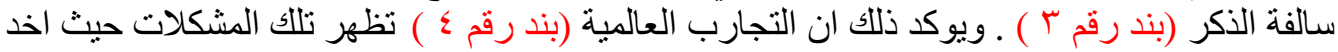

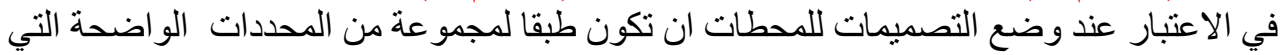

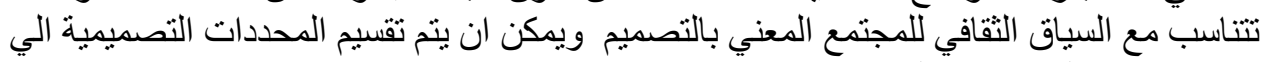

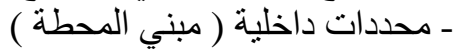

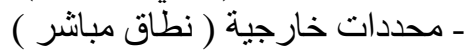

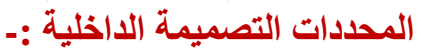

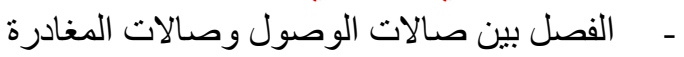

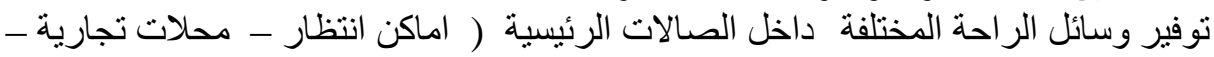

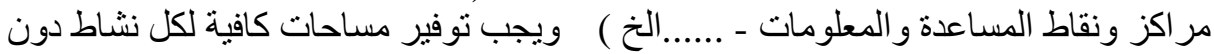
التعارض مع غيره

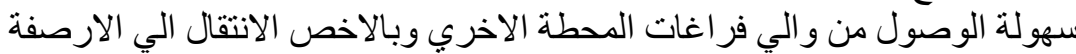

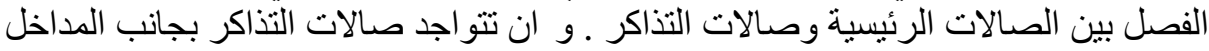

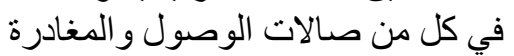
توفير اماكن انتظار خاصة لصالات التذاكر وتحتوي علي بعض شاثنات العرض لمساعدة الجمهور

تصمم صالات التذاكر لاستيعاب الركاب في ساعات الذروة

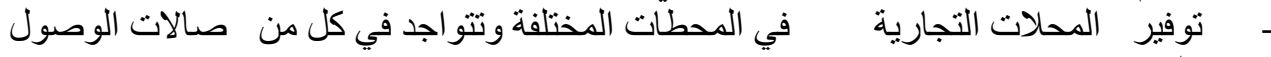
و المغادرة تقسم الارصفة الي مناطق محذور الوقوف بها وهي مناطي مناطق حرم الرصيف ومناطق الثريط

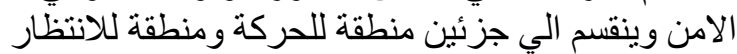

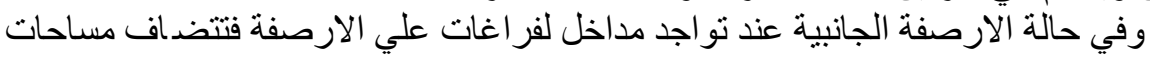

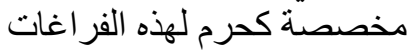
تخصيص جزء من القطاع العرضي للارصفة لاغرة للخدمات المتمثلة في ( لوحات معلومات القطار

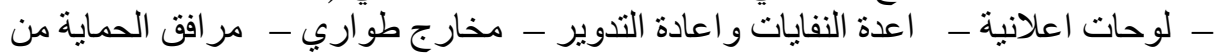

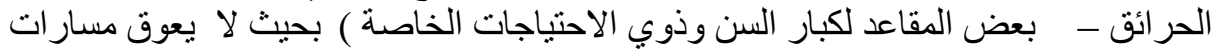

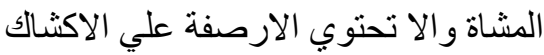

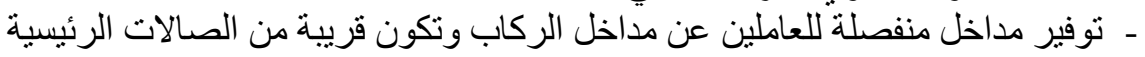

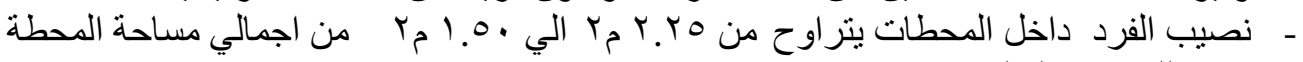
وفقا للتجارب العالمية

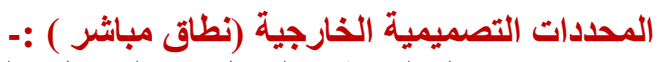

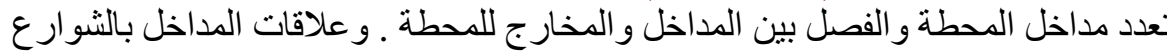
المجاورة

توفر مدخل المحطة الربط بين المحطة والمناطق المحيطة و يسهل تصميم المحطة عمليات

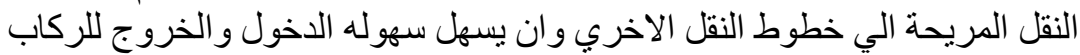

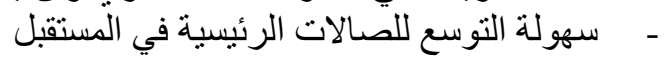

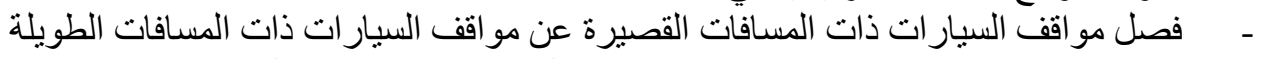
وتوفير مساحات اضافية لاستيعاب اكبر عدد من السيار ات في ساعات الذات الذروة • 


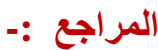

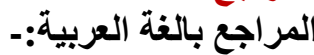

ا ـ الهية السكك الحديدية في تفعيل قطاع النقل ، در اسة بحثية ، المجلة العلمية للاقتصاد و التجارة ، مصر ،

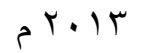

r. اسس ومعايير التنسيق الحضاري لمر اكز المدن ، در اسة بحثية ، المجلس الاعلي للتخطيط و التنمية العمر انية

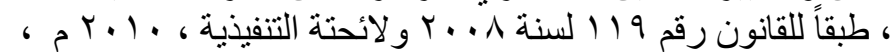

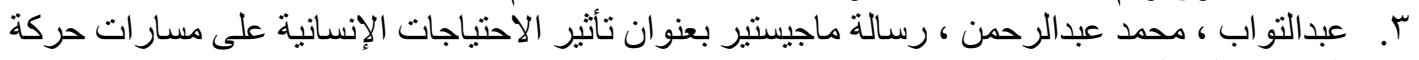

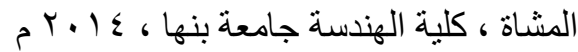

ـ. مشروع تطوير محطات السكك الحديديه ،در اسه بحثيه ،وحده التصميمات و البحوث و والدر اسات المعماريه

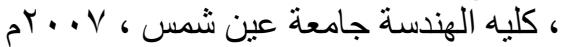

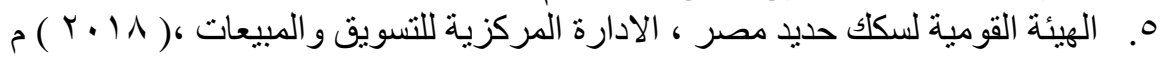

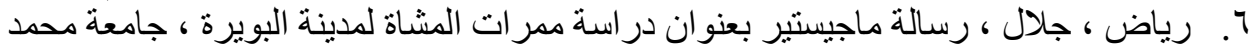

\section{المراجع بالغة الانجليزية : - المبل}

1. Cairo vision 2050, The Strategic Urban Development Plan of Greater Cairo Region

2. Manual for standards and specifications for railway stations, Ministry of Railways, Government of India, June 2009

3. Design standards for accessible rail stations, a joint code of Practice by the Department for Transport and Transport Britain, march 2015 